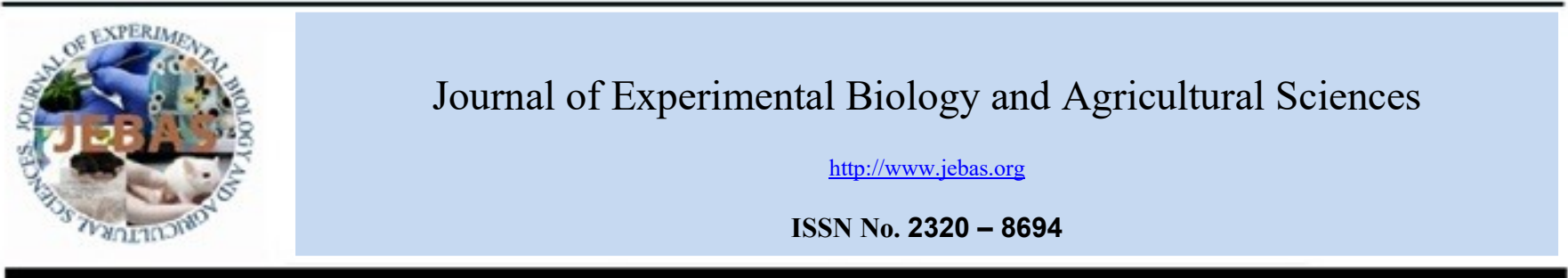

\title{
ECO-FRIENDLY EXTRACTION AND CHARACTERIZATION OF CELLULOSE FROM FENUGREEK (Trigonella foenum-gracum L.) STEM
}

\author{
Uma Hapani $^{1 *}$, Hyacinth Highland ${ }^{2}$, Linz-Buoy George ${ }^{2}$ \\ ${ }^{1}$ Department of Environmental Science, School of Sciences, Gujarat University, Ahemdabad-380009, Gujarat, India \\ ${ }^{2}$ Department of Zoology, Biomedical Technology and Human Genetics, School of Sciences, Gujarat university, Ahmedabad-380009, Gujarat, India \\ Received - June 10, 2020; Revision - July 28, 2020; Accepted - August 20, 2020 \\ Available Online - August 25, 2020
}

DOI: http://dx.doi.org/10.18006/2020.8(4).479.488

KEYWORDS
Cellulose
Fenugreek stem
FT-IR
XRD
DSC
SEM

\begin{abstract}
Recently, cellulose and its application acquire more attraction in the research and industrial sector due to its desirable properties like its a biopolymer, environment-friendly, inexhaustible, and its thermal and chemical stability are also high when fused with composites preparation. The present study reports an ecofriendly process that involved de-waxing, alkali, and bleaching treatments to extract cellulose from the Fenugreek stems (FS). The fenugreek stems are the chief agricultural wastes in India and can consider as absolute raw material for cellulose extraction. The obtained cellulose was characterized along with commercial cellulose to compare the efficiency of the extracted cellulose for its various properties viz., purity, presence or absence of hemicellulose, and lignin, crystallization, thermal stability, and surface morphology. The FT-IR (Fourier transform infrared spectroscopy) analysis revealed the successful removal of lignin and hemicellulose functionality. The crystallinity index obtained from XRD (X-ray diffractograms) for commercial and fenugreek cellulose found to be $55.11 \%$ and $54.68 \%$. The DSC (Differential scanning calorimetry) analysis confirms that extracted cellulose has $\left(318^{\circ} \mathrm{C}\right.$ to $\left.352^{\circ} \mathrm{C}\right)$ better thermal stability than of raw fenugreek sample $\left(314^{\circ} \mathrm{C}\right.$ to $\left.346^{\circ} \mathrm{C}\right)$. The SEM (Scanning electron microscopy) confirms that extracted cellulose has a rough and less bulky surface, which indicates the removal of non-cellulosic constituents. The results confirm that applied method gives high-grade quality and a $74 \%$ yield of cellulose, which can apply in the preparation of future biopolymer composites.
\end{abstract}

* Corresponding author

E-mail: umahapani18@gmail.com (Uma Hapani)

Peer review under responsibility of Journal of Experimental Biology and Agricultural Sciences.

Production and Hosting by Horizon Publisher India [HPI] (http://www.horizonpublisherindia.in/).

All rights reserved.
All the articles published by Journal of Experimental Biology and Agricultural Sciences are licensed under a Creative Commons Attribution-NonCommercial 4.0 International License Based on a work at www.jebas.org.






\section{Introduction}

Agricultural waste is generated in large amount throughout the year remains the most abundant renewable resource on the globe. Agricultural wastes mainly include stalk, stem, leaf, hull, shell, bark, legumes, hay, pulp or stubble from fruits, bagasse generated from sugarcane, and many others, which is generated after crop harvesting. These agricultural wastes are highly comprised of cellulose, hemicellulose, lignin, sugars, fibers, proteins, pectin, and minerals (Abdullah et al., 2020; Huaa et al., 2020; Song et al., 2020). There is a great interest in the reuse of agricultural wastes, both from environmental and commercial viewpoints. The environmental concern is when it's disposed to the nature or burn in the field may cause soil, water, and air pollution. The economic view is to produce cellulose fibers from locally available agricultural waste to avoid high transportation costs of the raw materials (Palma et al., 2011; Sundarraj \& Ranganathan, 2018; Kassab et al., 2020). Due to the limitation of non-renewable resources in recent years, the demand for cellulose-based renewable materials has been increasing (Mohanty et al., 2005).

Cellulose is a prominent component of all green plants. It is polysaccharides comprise of a linear chain of several thousands of $\beta(1 \rightarrow 4)$ linked D-glucopyranose monomer units (Wyman et al., 2005). Cellulose is extensively utilizing as commercial material due to its attractive characteristics such as biocompatibility, biodegradability, lightweight, renewable, thermal, and chemical stability (Sharma et al., 2019; Ma et al., 2020). Cellulose has also served as construction material, mainly in the form of intact wood and textile fibers or in the form of paper and board. A variety of stable cellulose derivatives like cellulose esters and cellulose ethers reported, which used in numerous areas of pharmaceutics and cosmetic industries. In the pharmaceutical, it's used as delayed-release coated dosage forms, controlled release matrices, osmotic drug delivery systems, bioadhesives, as thickening agents, and as stabilizers in liquid dosage preparation. These derivatives have also used as filler, taste masker, free-flowing agents, and pressure-sensitive adhesives in the cosmetic industry (Shokri\& Adibkia, 2013; Kavitha et al., 2020; Xu et al., 2020).

From the agricultural wastes, pure cellulose can be extracted by applying different pretreatments. It includes physical, chemical, and biological treatments. The physical treatment involves biomass size reduction, steam explosion, hydrothermal, and microwaveassisted. The chemical treatment includes the usage of alkaline, acidic, ionic liquid, and organic solvents. The biological treatment includes the usage of bacteria and fungi. These pretreatments help in eliminating non-cellulosic constitutes and reduce the particle size of agricultural wastes (Bhatia et al., 2020; Rezania et al., 2020; Sankaran et al., 2020). Various agro-wastes that have been already used for cellulose extraction are wheat straw, mulberry bark, coconut husk (Johar et al., 2012), garlic stalk, onion skin (Reddy \& Rhim, 2018), bagasse, bamboo, hemp, jute, oil palm, sisal (John \& Anandjiwala, 2008).

Fenugreek (Trigonella foenum-gracum L.) is cultivated worldwide as a semi-arid crop. Its seeds and leaves are used as ingredients in food as well as in medicinal applications such as antibacterial, anticancer, antiulcer, antioxidant, hypoglycaemic, and antidiabetic agents (Murlidhar \& Goswami, 2012; Srivastava et al., 2020). Major fenugreek producing countries are Afghanistan, Argentina, Bangladesh, Egypt, France, India, Iran, Morocco, Nepal, Pakistan, Spain, and Turkey. India is the largest producer of fenugreek in the world by the production of 45,000-55,000 tons per year (Vidyashankar, 2014; Yao et al., 2019). India's major producer states are Gujarat, Haryana, Madhya Pradesh, Maharashtra, Punjab, Rajasthan, Uttar Pradesh, and Uttarakhand. Rajasthan accounts for over $80 \%$ of India's total output (Lal et al., 2014; Parthasarathy et al., 2008).

The main aim of the present study is to design a new and low-cost eco-friendly method for the extraction of cellulose from the fenugreek stems. In the present study, for the first time fenugreek stems used as starting material for the extraction of cellulose. Not yet an early study reported on fenugreek stem, which used as raw material for cellulose extraction. It is inexpensive and locally available in large quantities in India. In the part of the study, commercial cellulose was used as reference material to check the purity of extracted cellulose in order to extend the validity of our conclusions.

\section{Materials and Methods}

\subsection{Materials}

Fenugreek stems utilized in the experiment were collected from the local farm of the Amreli district, Gujarat, India. Stems were extensively washed with distilled water to remove impurities mainly dust. The materials were shaded dry and chopped into small pieces and milled to pass through $2 \mathrm{~mm}$ mesh. The milled samples then stored at room temperature. The reagents and chemical used in the study such as n-Hexane (99\%, Merck), methanol (99\%, Astron chemicals India), sodium hydroxide (HIMEDIA), commercial cellulose powder (97\%, HIMEDIA), maleic acid (99\%, HIMEDIA), citric acid (99\%, HIMEDIA), hydrogen peroxide (50\%, Astron chemicals India), and other chemicals were of standard analytical grades.

\subsection{Extraction of Cellulose from Fenugreek stem}

A various study reported that the lower alkali concentration was favorable for cellulose extraction from agricultural wastes. In the alkali solution, lignin and hemicellulose are hydrolyzed and 
becomes water-soluble. Mandal \& Chakrabarty (2011) reported that, addition of acid in the bleaching treatment helps to disintegrate cellulose fibers. Similar facts were reported by Mwaikambo \& Ansell (2002) and Cherian et al. (2010). In the present work, we drafted a new eco-friendly method to extract cellulose from the fenugreek stem. For the production of the maximum yield of cellulose from the fenugreek stem, in current study different concentration of $\mathrm{NaOH}$ solutions was added in the alkali and citric acid solutions of the bleaching treatment. On the based of the results, the optimized method is given in figure 1. Extracted cellulose kept in an airtight container for further analysis at room temperature. The cellulose yield (\%) was determined by using Leão et al. (2017) equation.

Cellulose Yield $(\%)=\frac{M p}{M s} \times 100$

Where as $M p$ is the mass of final product

Ms is the mass of raw sample

\subsection{Characterization}

The extracted cellulose was characterized using following techniques which confirms the purity of fenugreek cellulose.

\subsubsection{Fourier Transform Infrared Spectroscopy (FTIR)}

The functional group and chemical structure of samples were evaluated by FT-IR spectroscopy using the BRUKER ALPHA-II ATR-FTIR (Germany) spectrometer in the region from 4000 to $400 \mathrm{~cm}^{-1}$ and a total of 32 scans for each sample.

\subsubsection{X-ray diffraction (XRD)}

The X-ray diffraction of the samples were carried out using RIGAKU ULTIMA IV Powder X-Ray Diffractometer (Tokyo, Japan), with $\mathrm{CuK} \alpha$ radiation $\left(\lambda=1.54 \mathrm{~A}^{\circ}\right)$. The crystallinity index (CI) of the samples was calculated according to the Segal et al. (1959) equation.

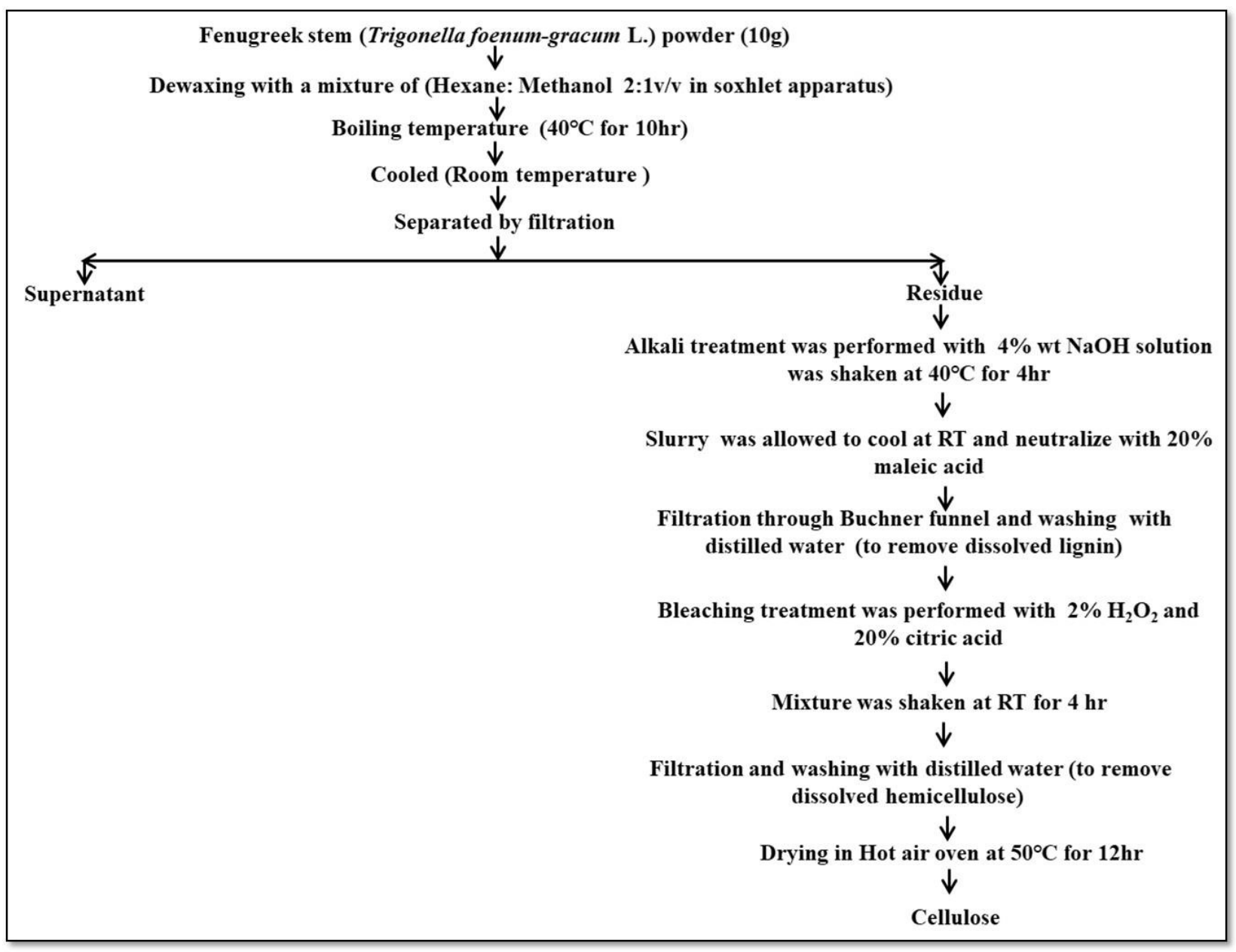

Figure 1 Extraction of cellulose from fenugreek stem

Journal of Experimental Biology and Agricultural Sciences http://www.jebas.org 
Table 1 Optimization of fenugreek cellulose extraction process

\begin{tabular}{|c|c|c|c|c|c|c|}
\hline $\begin{array}{l}\text { Sample } \\
\text { No. }\end{array}$ & $\begin{array}{c}\text { Concentration of } \\
\mathrm{NaOH}\end{array}$ & $\operatorname{Acid}^{\mathrm{a}}$ & Temp. $\left({ }^{\circ} \mathrm{C}\right)$ & Time (hr) & $\begin{array}{c}\text { Cellulose } \\
\text { Weight (gms) }\end{array}$ & $\begin{array}{l}\text { Cellulose } \\
\text { yield (\%) }\end{array}$ \\
\hline 1 & $1 \%$ wt $\mathrm{NaOH}$ & Citric acid 5\% & 10 & 1 & 5.8 & 58 \\
\hline 2 & $2 \%$ wt $\mathrm{NaOH}$ & Citric acid $10 \%$ & 20 & 2 & 6.2 & 62 \\
\hline 3 & $3 \%$ wt $\mathrm{NaOH}$ & Citric acid 15\% & 30 & 3 & 6.7 & 67 \\
\hline 4 & $4 \%$ wt $\mathrm{NaOH}$ & Citric acid $20 \%$ & 40 & 4 & 7.4 & 74 \\
\hline 5 & $5 \%$ wt $\mathrm{NaOH}$ & Citric acid $25 \%$ & 50 & 5 & 7.0 & 70 \\
\hline
\end{tabular}

Results have been taken on the basis of average of minimum triplet repeated process; Initial weight of the raw fenugreek sample = 10g,

${ }^{a}$ Different concentrations of citric acid taken into bleaching process.

$\operatorname{Crl}(\%)=\frac{\left(I_{002}-I_{a m}\right)}{I_{002}} \times 100$

Where: $\mathrm{Crl}$ the relative degree of crystallinity, $I_{002}$ is the intensity of the highest intensity peak which arises from both crystalline and amorphous regions and $I_{a m}$ is the intensity of the amorphous peak.

\subsubsection{Differential scanning calorimetry (DSC)}

Using Shimadzu DSC-60 Plus (Kyoto, Japan) differential scanning calorimeter the thermal behaviour of samples were studied. Each sample was heated from $30^{\circ} \mathrm{C}$ to $400^{\circ} \mathrm{C}$ at a heating rate of $10^{\circ} \mathrm{C} / \mathrm{min}$ under the nitrogen atmosphere. For this $7 \mathrm{mg}$ sample was weighed using hermetically sealed pans with a pinhole in the lid. The thermograms indicated the onset of melting temperature and crystallization temperature of the samples.

\subsubsection{Scanning electron microscopy (SEM)}

The surface morphology of the samples were investigated by using scanning electron microscope (SEM). The photographs of sample surfaces were captured using Scanning Electron Microscope XL 30 ESEM EDAX (Philips, Netherland). The samples were coated over double side carbon tape. The accelerating voltage was $10 \mathrm{kV}$.

\section{Results and Discussion}

\subsection{Yield of Cellulose (\%)}

The cellulose extraction process was optimized in five different reactions. The reaction parameters like concentration of $\mathrm{NaOH}$, time, temperature, and concentration of citric acid examined to evaluate the optimum reaction conditions. The obtained results presented in table 1 . In the fenugreek stem, cellulose is surrounded by hemicellulose, lignin, wax, and other cementing materials. For the removal of these materials, alkali treatment performed using sodium hydroxide $(\mathrm{NaOH})$. The concentration of sodium hydroxide, time of the treatment, and operating temperature mainly affect on the yield and properties of cellulose. From table 1 it is clearly observed if alkali treatment performed at a high temperature for a long duration with a high concentration of sodium hydroxide, cellulose crystal parts start to degrade which results in a lower yield of cellulose. Citric acids taken into bleaching treatments helps in the elimination of the rest of hemicellulose and improve the properties of cellulose (Bartos et al., 2020; Baskaran et al., 2020; Xia et al., 2020). The optimum conditions of the reactions were $4 \%$ wt $\mathrm{NaOH}$, for $4 \mathrm{hr}$, at $40{ }^{\circ} \mathrm{C}$ with $20 \%$ citric acid, where maximum yield $74 \%$ of cellulose was recovered.

\subsection{Fourier Transform Infrared Spectroscopy (FTIR)}

FT-IR spectra of commercial and fenugreek cellulose have been shown in figure 2. A strong band appeared at $3500 \mathrm{~cm}^{-1}-3000 \mathrm{~cm}^{-}$ ${ }^{1}$, which is associated with the stretching vibration of $\mathrm{O}-\mathrm{H}$ groups having strong inter and intra-molecular H-bonding (Kamsonlian et al., 2011; Paniz et al., 2020). The stretching frequency at 2893 $\mathrm{cm}^{-1}$ and $2904 \mathrm{~cm}^{-1}$ was due to the symmetric C-H group of cellulose (Rosa et al., 2012; Galiwango et al., 2019). The band at $1736 \mathrm{~cm}^{-1}$ corresponds to the carbonyl group $(\mathrm{C}=\mathrm{O})$ due to the presence of acetyl ester and carbonyl aldehyde groups of hemicellulose (Ventura-Cruz \& Tecante, 2019; da Silva \& Poletto, 2020; Hussin et al., 2020). This band completely disappeared in the extracted cellulose because of the removal of most of the hemicellulose. The peaks at 1254, 1508 and $1604 \mathrm{~cm}^{-1}$ correspond to the aromatic skeletal vibrations of lignin (Morán et al., 2008, De et al., 2020). These peaks are absent in fenugreek cellulose indicating the complete removal of lignin. The absorption band at $1163 \mathrm{~cm}^{-1}$ corresponds to the $\mathrm{C}-\mathrm{O}$ antisymmetric bridge stretching of cellulose (Lubis et al., 2019; Khan et al., 2020).

The absorption bands at 1110 and $1055 \mathrm{~cm}^{-1}$ correspond to C-O-C the $\beta$-1, 4-glycosidic ring linkages between the D-glucose units in cellulose (Tarchoun et al., 2019; Kalpana \& Perarasu, 2020). The peaks at 1061 and $897 \mathrm{~cm}^{-1}$ are associated with cellulose, the C-O stretching, and the $\mathrm{C}-\mathrm{H}$ rock vibrations of the cellulose (Trilokesh \& Uppuluri, 2019; Shaker et al., 2020). The sharp signals at 895 $\mathrm{cm}^{-1}$ of fenugreek cellulose and commercial cellulose reflect the crystalline band of cellulose (Fan et al., 2012). 


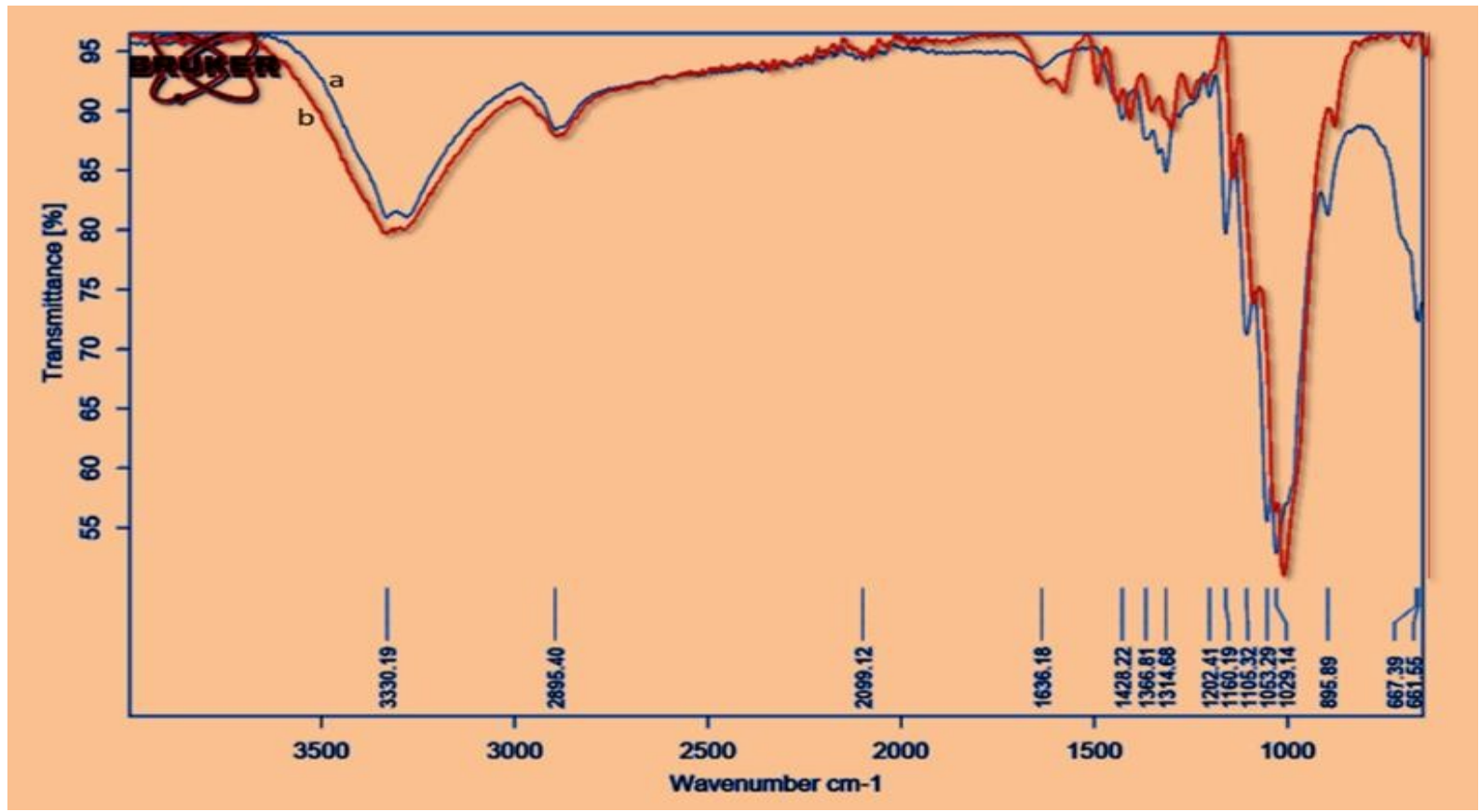

Figure 2 FT-IR Spectra of - (a) Commercial cellulose (b) Fenugreek cellulose


Figure 3 XRD patterns of (a) Commercial cellulose (b) Fenugreek cellulose

\subsection{X-ray diffraction (XRD)}

XRD patterns of commercial and fenugreek cellulose have been represented by figure 3 . The XRD pattern of commercial cellulose shows three well-defined peaks at $2 \theta=15.80^{\circ}, 22.88^{\circ}$, and $35.20^{\circ}$. Similarly, XRD patterns of fenugreek cellulose also showed three peaks at $2 \theta=15.10^{\circ}, 22.63^{\circ}$, and $34.53^{\circ}$. Table 2 represents the $2 \theta$ peak values of commercial and fenugreek cellulose The broad peak at $2 \theta=15.10^{\circ}$, corresponds to the (110) crystallographic plane This peak is more evident that the sample enclosed with more amorphous material, such as lignin, hemicelluloses, pectin, and oil/wax. The broad peak at $2 \theta=22.63^{\circ}$, corresponds to the (002) crystallographic plane (Melikoğlu et al., 2019; Gu et al., 2020). These shows the possible relaxation of stress in the cellulose chains as a result of the removal of its amorphous constituents (Li et al., 2009; Sutrisno et al., 2020). The crystallinity index of the fenugreek stem has been increasing after the removal of non-cellulosic constituents. It is possible after alkali treatment, it produces cleavage in the hydrogen bonds, which leads to the removal of cementing materials (Wang et al., 2019). The crystallinity index obtained from X-ray diffractograms for commercial and fenugreek cellulose found to be $55.11 \%$ and $54.68 \%$ respectively. 
Table 2 Crystallinity index ( $\mathrm{Crl})$ of commercial cellulose and fenugreek cellulose

\begin{tabular}{|c|c|c|c|c|c|c|c|}
\hline Sample & 2-theta (deg) & D (ang.) & Height (counts) & FWHM (deg) & Int. I (counts deg) & Int. W (deg) & Size (ang.) \\
\hline \multirow{3}{*}{$\begin{array}{l}\text { Commercial } \\
\text { cellulose }\end{array}$} & 15.80 & 5.604 & 568 & 4.77 & 4062 & 7.2 & 17.6 \\
\hline & 22.88 & 3.883 & 1091 & 2.62 & 3961 & 3.63 & 32.3 \\
\hline & 35.20 & 2.548 & 73 & 3.7 & 582 & 7.9 & 23 \\
\hline \multirow{3}{*}{$\begin{array}{c}\text { Fenugreek } \\
\text { cellulose }\end{array}$} & 15.10 & 5.864 & 1008 & 2.70 & 3766 & 3.74 & 31.0 \\
\hline & 22.63 & 3.925 & 2597 & 1.73 & 6774 & 2.61 & 48.9 \\
\hline & 34.53 & 2.596 & 180 & 1.57 & 359 & 2.0 & 55 \\
\hline
\end{tabular}

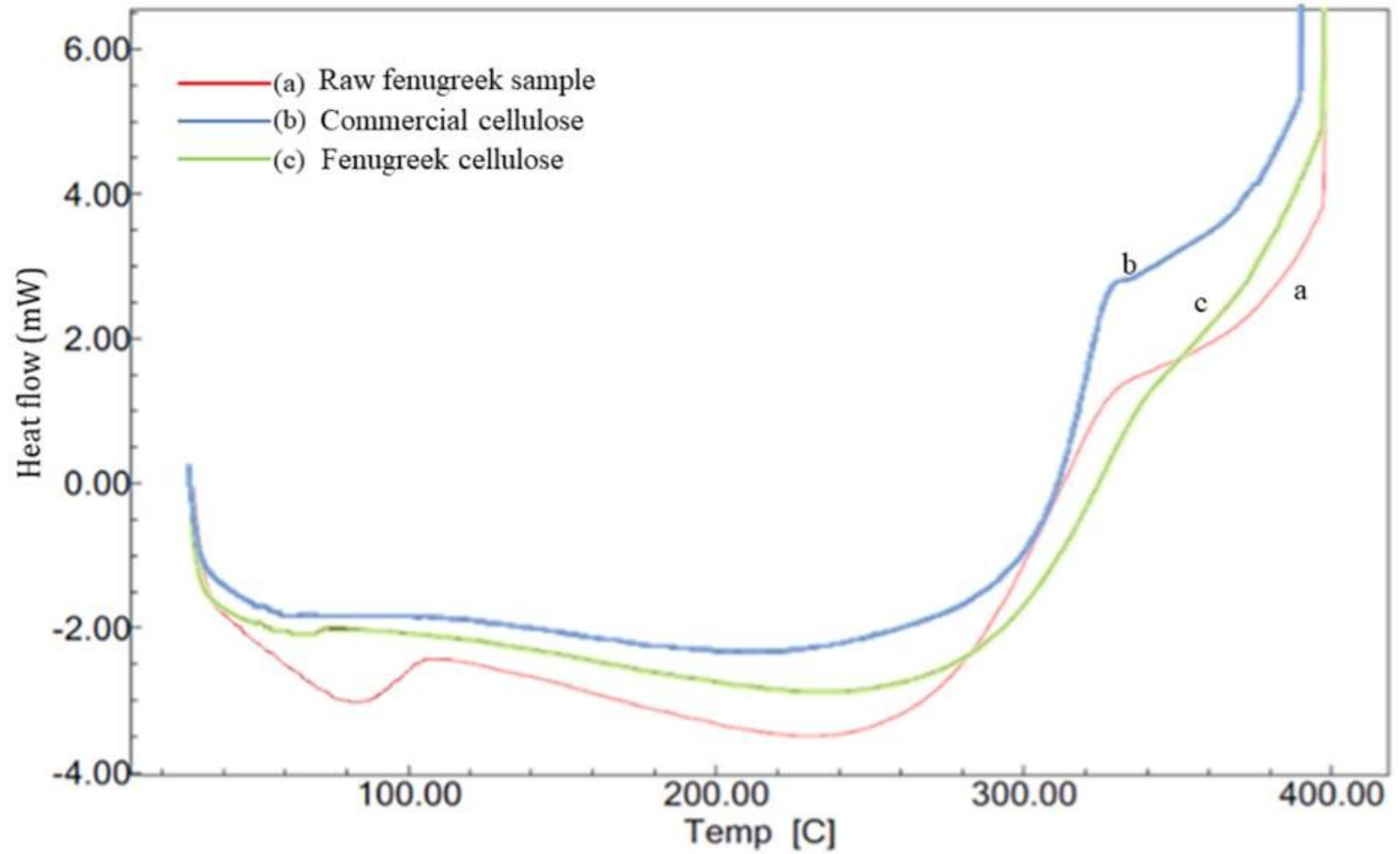

Figure 4 DSC curve of (a) Raw fenugreek sample (b) Commercial cellulose (C) Fenugreek cellulose

\subsection{Differential scanning calorimetry (DSC)}

Figure 4 shows the three DSC thermograms of raw fenugreek sample, commercial, and fenugreek cellulose. All three DSC thermograms exhibit two distinct endothermic changes within the temperature range of $30^{\circ} \mathrm{C}$ to $400^{\circ} \mathrm{C}$. However, the nature of endotherms is dependent on the composition of the materials. In all three thermograms, the first endothermic peak observed due to water evaporation from $50^{\circ} \mathrm{C}$ to near $100^{\circ} \mathrm{C}$ (Rasheed et al., 2020; Ufodike et al., 2020). Moreover, the amorphous character of the cellulosic material absorbs more water and shows a sharp endothermic peak. The above phenomenon rarely observed with crystalline cellulose. Therefore shows no or minimal peak lines (Mandal \& Chakrabarty, 2011). Similarly, Yang et al. (2007) report that thermal decomposition regions of cellulose are in the range of $315^{\circ} \mathrm{C}-400^{\circ} \mathrm{C}$. The melting point observed in the second endotherm in three cases describes the nature of the decomposition of the crystallites. The non-cellulosic constituents in the raw fenugreek sample make it less stable, whereby decreases the melting temperature in the range from $314^{\circ} \mathrm{C}$ to $346^{\circ} \mathrm{C}$.

The fenugreek cellulose loses a substantial amount of noncellulosic materials and thereby rearrange and reorients into crystalline form resulting in a compact structure. The resultant 

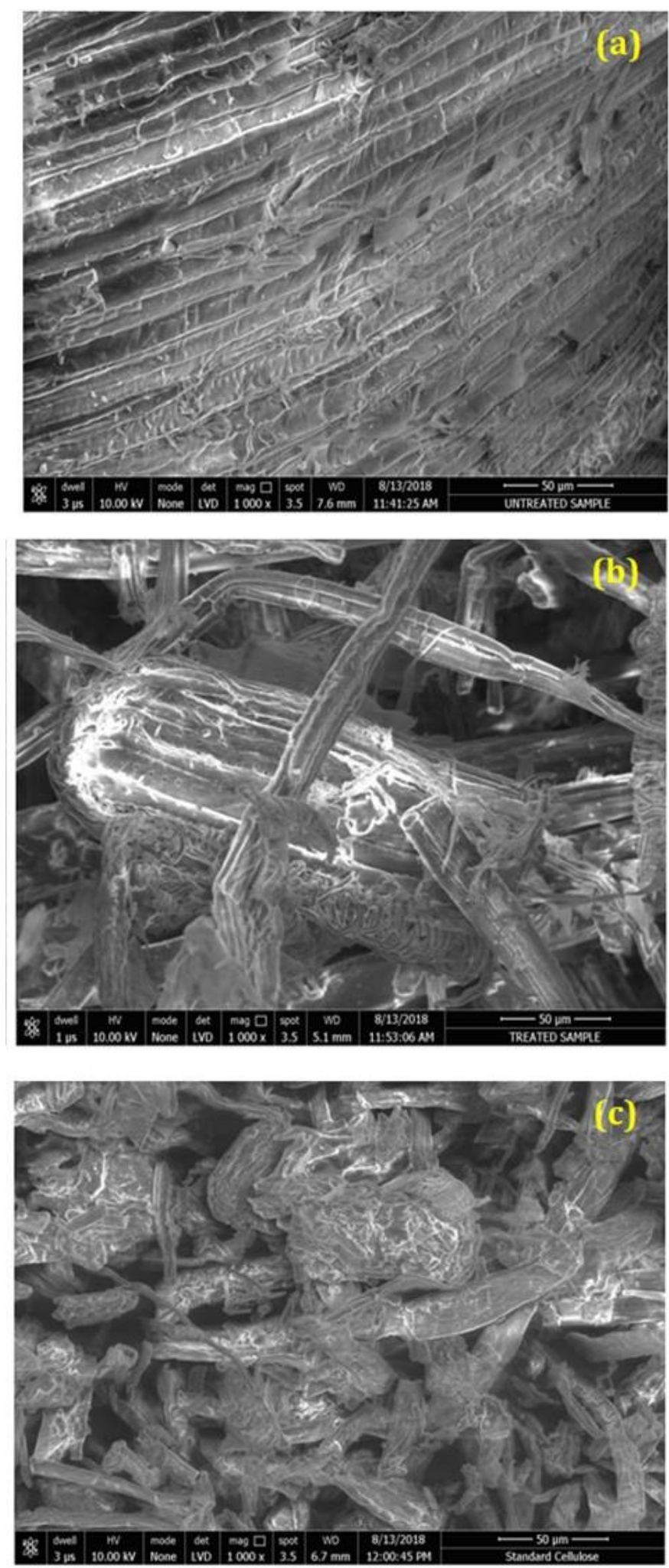

Figure 5 SEM micrograph of (a) Raw fenugreek sample (b) Fenugreek cellulose (C) Commercial cellulose fenugreek cellulose confirms a rise in the melting temperature from $318^{\circ} \mathrm{C}$ to $352^{\circ} \mathrm{C}$. The melting temperature range of fenugreek cellulose obtained from DSC confirms it is close to the commercial cellulose $316^{\circ} \mathrm{C}-359^{\circ} \mathrm{C}$.

\subsection{Scanning electron microscopy (SEM)}

SEM micrographs of the raw fenugreek sample, commercial, and fenugreek cellulose are illustrated in Figure 5. The raw fenugreek sample shows (figure 5a) a very smooth surface indicates the presence of non-cellulosic material such as lignin, hemicellulose, wax, and other cementing materials (Kian et al., 2020). Bleaching with $\mathrm{H}_{2} \mathrm{O}_{2}$ and citric acid helps to eliminate the rest of lignin-hemicellulose and besides disintegration leading to the development of pure cellulose. This was observed from figure $5 \mathrm{~b}$ that fenugreek cellulose has loose fibers, rough and less bulky appearance. Alkaline and bleaching treatment eliminates unwanted materials and increases the surface area of cellulose (Pereira et al., 2020). Furthermore, confirmation compares to commercial cellulose micrograph (figure $5 \mathrm{c}$ ) similar surface structure shown in the fenugreek cellulose micrograph.

\section{Conclusion}

Agricultural waste such as fenugreek stem is an attractive alternative source for cellulose extraction. Cellulose was extracted from the dewaxed fenugreek stem. An optimized process was given a $74 \%$ yield of cellulose. The FTIR spectroscopic revealed changes in functional groups of fenugreek cellulose indicate the removal of wax, lignin, and hemicelluloses functionalities. XRD analysis intimated crystallinity of fenugreek cellulose is similar to commercial cellulose. Further, based on the DSC analyses, fenugreek cellulose was found to exhibit better thermal stability than raw fenugreek sample which could stand with higher temperatures when infused with polymeric composites for future applications. The morphological examination by SEM indicated that a rougher and less bulky structure of fenugreek cellulose was obtained after the given treatments. The cellulose obtained from fenugreek stems has similar characteristics to commercial cellulose which has been finding potential applications as raw material for pulp and paper industry, as green composites, as water absorbents, or as raw materials for cellulose derivatives. This work may give a new path for the high utilization of fenugreek stem waste.

\section{Acknowledgments}

The authors admiringly acknowledge the financial support provided by the INSPIRE programme under the Assured

Journal of Experimental Biology and Agricultural Sciences http://www.jebas.org 
Opportunity for Research Careers (AORC) scheme, financed by The Department of Science and Technology (DST) (Sanction Order No.: DST/INSPIRE Fellowship/2016/IF160737, New Delhi, India.

\section{Conflict of Interest}

No potential conflict of interest was reported by the authors.

\section{References}

Abdullah NA, Sainorudin MH, Asim N, Mohammad M, AbdKadir NH, Yaakob Z (2020) Extraction of Microcrystalline Cellulose from Two Different Agriculture Waste via Chemical Treatment. In IOP Conference Series: Materials Science and Engineering, IOP Publishing 739: 012017.

Bartos A, Anggono J, Farkas ÁE, Kun D, Soetaredjo FE, Móczó J, Pukánszky B (2020) Alkali treatment of lignocellulosic fibers extracted from sugarcane bagasse: Composition, structure, properties. Polymer Testing 17: 106549.

Baskaran PG, Kathiresan M, Pandiarajan P (2020) Effect of Alkali-treatment on Structural, Thermal, Tensile Properties of DichrostachysCinerea Bark Fiber and Its Composites. Journal of Natural Fibers 6: 1-7.

Bhatia SK, Jagtap SS, Bedekar AA, Bhatia RK, Patel AK, Pant D, Yang YH (2020) Recent developments in pretreatment technologies on lignocellulosic biomass: Effect of key parameters, technological improvements, and challenges. Bioresource Technology 300: 122724.

Cherian BM, Leão AL, De Souza SF, Thomas S, Pothan LA, Kottaisamy M (2010) Isolation of nanocellulose from pineapple leaf fibres by steam explosion. Carbohydrate Polymers 81:720 725 .

da Silva Braga R, Poletto M (2020) Preparation and Characterization of Hemicellulose Films from Sugarcane Bagasse. Materials 13: 941

De S, Mishra S, Poonguzhali E, Rajesh M, Tamilarasan K (2020) Fractionation and characterization of lignin from waste rice straw: Biomass surface chemical composition analysis. International Journal of Biological Macromolecules 145: 795-803.

Fan M, Dai D, Huang B (2012) Fourier transform infrared spectroscopy for natural fibres. Fourier transform-materials analysis 3:45-68.

Galiwango E, Rahman NSA, Al-Marzouqi AH, Abu-Omar MM, Khaleel AA (2019) Isolation and characterization of cellulose and $\alpha$-cellulose from date palm biomass waste. Heliyon 5: e02937.
Gu H, Gao X, Zhang H, Chen K, Peng L (2020) Fabrication and characterization of cellulose nanoparticles from maize stalk pith via ultrasonic-mediated cationic etherification. Ultrasonics Sonochemistry 66: 104932 .

Huaa YL, Haruna S, Sajaba MS, Jahima JM, Shahb SSM (2020) Extraction of Cellulose and Microcrystalline Cellulose from Kenaf. Jurnal Kejuruteraan 32: 205-213.

Hussin FNNM, Attan N, Wahab RA (2020) Extraction and characterization of nanocellulose from raw oil palm leaves (Elaeisguineensis). Arabian Journal for Science and Engineering 45: 175-186.

Johar N, Ahmad I, Dufresne A (2012) Extraction, preparation and characterization of cellulose fibres and nanocrystals from rice husk. Industrial Crops and Products 37:93-99.

John MJ, Anandjiwala RD (2008) Recent developments in chemical modification and characterization of natural fiber reinforced composites. Polymer composites 29:187-207.

Kalpana VP, Perarasu VT (2020) Analysis on cellulose extraction from hybrid biomass for improved crystallinity. Journal of Molecular Structure 30: 128350.

Kamsonlian S, Suresh S, Majumder CB, Chand S (2011) Characterization of banana and orange peels: biosorption mechanism. International Journal of Science Technology and Management 2:1-7.

Kassab Z, Kassem I, Hannache H, Bouhfid R, El Achaby M (2020) Tomato plant residue as new renewable source for cellulose production: Extraction of cellulose nanocrystals with different surface functionalities. Cellulose 17: 1-17.

Kavitha AA, Paul KT, Anilkumar P (2020) Cellulose-derived materials for drug delivery applications. Sustainable Nanocellulose and Nanohydrogels from Natural Sources Elsevier: 367-390.

Khan MN, Rehman N, Sharif A, Ahmed E, Farooqi ZH, Din MI (2020) Environmentally benign extraction of cellulose from dunchi fiber for nanocellulose fabrication. International Journal of Biological Macromolecules 153: 72-78.

Kian LK, Saba N, Jawaid M, Fouad H (2020) Characterization of microcrystalline cellulose extracted from olive fiber. International Journal of Biological Macromolecules 156: 347-353.

Lal GS, Parmeshwar LD, Ganga BD, Raj R (2014) Production technology of fenugreek (Trigonella foenum-graecum L.). Advances in vegetable agronomy, Publisher: Indian Council of Agricultural Research: 244-250. 
Leão RM, Miléo PC, Maia JM, Luz SM (2017) Environmental and technical feasibility of cellulose nanocrystal manufacturing from sugarcane bagasse. Carbohydrate polymers 175:518-529.

Li R, Fei J, Cai Y, Li Y, Feng J, Yao J (2009) Cellulose whiskers extracted from mulberry: A novel biomass production. Carbohydrate Polymers 76:94-99.

Lubis R, Wirjosentono B, Septevani A (2019) Extraction and characterization of cellulose fiber of durian rinds from north sumatera as the raw material for textile fiber. In Journal of Physics: Conference Series. IOP Publishing: 012017.

Ma W, Qin Y, Li Y, Chai J, Zhang X, Ma Y, Liu H (2020) Mechanical properties and engineering application of cellulose fiber-reinforced concrete. Materials Today Communications 22: 100818 .

Mandal A, Chakrabarty D (2011) Isolation of nanocellulose from waste sugarcane bagasse (SCB) and its characterization. Carbohydrate Polymers 86:1291-1299.

Melikoğlu AY, Bilek SE, Cesur S (2019) Optimum alkaline treatment parameters for the extraction of cellulose and production of cellulose nanocrystals from apple pomace. Carbohydrate polymers 215 : 330-337.

Mohanty AK, Misra M, Drzal LT, Selke SE, Harte BR, Hinrichsen G (2005) Natural fibers, Biopolymers and Biocomposites: An Introduction. In: Mohanty AK, Misra M, Drzal LT (Eds.) "Natural Fibers, Biopolymers, and Biocomposites", CRC Press, London.

Morán JI, Alvarez VA, Cyras VP, Vázquez A (2008) Extraction of cellulose and preparation of nanocellulose from sisal fibers. Cellulose 15:149-159.

Murlidhar M, Goswami TK (2012) A review on the functional properties, nutritional content, medicinal utilization and potential application of fenugreek. Journal of Food Processing and Technology 3: 9.

Mwaikambo LY, Ansell MP (2002) Chemical modification of hemp, sisal, jute, and kapok fibers by alkalization. Journal of Applied Polymer Science 84:2222-2234.

Palma C, Contreras E, Urra J, Martínez MJ (2011) Eco-friendly technologies based on banana peel use for the decolourization of the dyeing process wastewater. Waste and Biomass Valorization 2:77-86

Paniz OG, Pereira CM, Pacheco BS, Wolke SI, Maron GK, Mansilla A, Carreño NL (2020) Cellulosic material obtained from Antarctic algae biomass. Cellulose 27: 113-126.
Parthasarathy VA, Kandinnan K, Srinivasan V (2008) "Fenugreek" Organic Spices. New India Publishing Agencies: 694.

Pereira PHF, Souza NF, Ornaghi Jr HL, de Freitas MR (2020) Comparative analysis of different chlorine-free extraction on oil palm mesocarp fiber. Industrial Crops and Products 150: 112305.

Rasheed M, Jawaid M, Parveez B, Zuriyati A, Khan A (2020) Morphological, chemical and thermal analysis of cellulose nanocrystals extracted from bamboo fibre. International Journal of Biological Macromolecules 160: 183-191.

Reddy JP, Rhim JW (2018) Extraction and characterization of cellulose microfibers from agricultural wastes of onion and garlic. Journal of Natural Fibers 15:465-73.

Rezania S, Oryani B, Cho J, Talaiekhozani A, Sabbagh F, Hashemi B, Mohammadi AA (2020) Different pretreatment technologies of lignocellulosic biomass for bioethanol production: An overview. Energy 29: 117457.

Rosa SM, Rehman N, de Miranda MI, Nachtigall SM, Bica CI (2012) Chlorine-free extraction of cellulose from rice husk and whisker isolation. Carbohydrate Polymers 87:1131-1138.

Sankaran R, Cruz RAP, Pakalapati H, Show PL, Ling TC, Chen WH, Tao Y (2020) Recent advances in the pretreatment of microalgal and lignocellulosic biomass: A comprehensive review. Bioresource technology 298: 122476.

Segal LG, Creely JJ, Martin Jr AE, Conrad CM (1959) An empirical method for estimating the degree of crystallinity of native cellulose using the X-ray diffractometer. Textile research journal 29:786-794.

Shaker K, Khan RMWU, Jabbar M, Umair M, Tariq A, Kashif M, Nawab Y (2020) Extraction and characterization of novel fibers from Vernoniae laeagnifolia as a potential textile fiber. Industrial Crops and Products 152: 112518.

Sharma A, Thakur M, Bhattacharya M, Mandal T, Goswami S (2019) Commercial application of cellulose nanocomposites-A review. Biotechnology Reports 21: 00316.

Shokri J, Adibkia K (2013) Application of cellulose and cellulose derivatives in pharmaceutical industries. In: Ven TVD, Godbout (Eds.).Cellulose-medical, pharmaceutical and electronic applications. Rijeka, Croatia: IntechOpen.

Song H, Jia H, Wang Q, Zhao X, Yang G, Zhang M, Ma L (2020) A New Environmentally-Friendly System for Extracting Cellulose from Corn Straw: The Low Temperature Laccase System. Materials 13: 437. 
Srivastava A, Singh Z, Verma V, Choedon T (2020) Potential Health Benefits of Fenugreek With Multiple Pharmacological Properties. In Ethnopharmacological Investigation of Indian Spices. IGI Global pp: 137-153.

Sundarraj AA, Ranganathan TV (2018) Extraction and characterization of cellulose from jackfruit (Artocarpus integer) Peel. Journal of Experimental Biology and Agricultural Sciences $6: 414-424$.

Sutrisno E, Tanpichai S, Chuangchote S (2020) Isolation and characterization of cellulose nanofibers (CNFs) from Macaranga hypoleuca. In IOP Conference Series: Earth and Environmental Science. IOP Publishing: 012003.

Tarchoun AF, Trache D, Klapötke TM (2019) Microcrystalline cellulose from Posidoniaoceanica brown algae: Extraction and characterization. International journal of biological macromolecules 138: 837-845.

Trilokesh C, Uppuluri KB (2019) Isolation and characterization of cellulose nanocrystals from jackfruit peel. Scientific reports 9: 1-8.

Ufodike CO, Eze VO, Ahmed MF, Oluwalowo A, Park JG, Okoli OI, Wang H (2020) Evaluation of the inter-particle interference of cellulose and lignin in lignocellulosic materials. International Journal of Biological Macromolecules 147: 762-767.

Ventura-Cruz S, Tecante A (2019) Extraction and characterization of cellulose nanofibers from Rose stems (Rosa spp.). Carbohydrate polymers 220: 53-59.
Vidyashankar GK (2014) Fenugreek: An analysis from trade and commerce perspective. American Journal of Social Issues and Humanities: 16270.

Wang J, Liu M, Duan C, Sun J, Xu Y (2019) Preparation and characterization of cellulose-based adsorbent and its application in heavy metal ions removal. Carbohydrate polymers 206: 837-843.

Wyman CE, Decker SR, Himmel ME, Brady JW, Skopec CE, Viikari L (2005) Hydrolysis of cellulose and hemicellulose. Polysaccharides: Structural diversity and functional versatility 1:1023-1062.

Xia L, Zhang C, Wang A, Wang Y, Xu W (2020) Morphologies and properties of Juncuseffusus fiber after alkali treatment. Cellulose 27: 1909-1920.

Xu D, Teng G, Heng Y, Chen Z, Hu D (2020) Eco-friendly and thermally stable cellulose film prepared by phase inversion as supercapacitor separator. Materials Chemistry and Physics 30: 122979.

Yang H, Yan R, Chen H, Lee DH, Zheng C (2007) Characteristics of hemicellulose, cellulose and lignin pyrolysis. Fuel 86:17811788 .

Yao D, Zhang B, Zhu J, Zhang Q, Hu Y, Wang S, Xiao J (2019) Advances on application of fenugreek seeds as functional foods: Pharmacology, clinical application, products, patents and market. Critical Reviews in Food Science and Nutrition: 1-11. 